Impact of Electronic Monitoring on Employees: A Meta-Analysis

Rudolf Siegel $^{1}$, Cornelius J. König ${ }^{1}$, and Veronika Lazar ${ }^{1}$

${ }^{1}$ Saarland University

A preprint submission to PsyArxiv 


\begin{abstract}
Electronic monitoring is more and more widespread and affects many employees around the globe. The current meta analysis collected data of 59 independent samples (with 223 effect sizes) to estimate the effect of electronic monitoring on job satisfaction, stress, and performance. A random-effects model indicated a small negative effect of monitoring on job satisfaction, $r=-.10$, and a small positive effect on stress, $r=.13$. There was no relationship with performance, $r=-.01$. Even if the effects of monitoring on job satisfaction and stress are small, taking the large number of employees who are monitored for several hours a day into account, these effects may have a severe and negative impact on employees' well-being. Performance maintenance is the main justification for the use of electronic monitoring, but the non-existing relationship of monitoring with performance questions the validity of this justification.
\end{abstract}

Keywords: electronic monitoring; job satisfaction; stress; performance; employees; Word count: 6358 words (excluding references, figures, and tables) 


\section{Impact of Electronic Monitoring on Employees: A Meta-Analysis}

\section{Introduction}

Electronic monitoring of employees is a strongly debated topic since the 1980's (e.g., Irving et al., 1986; Tamuz, 1987). What is more, advances in technology led over the years to cheaper, more efficient, and easier to implement monitoring systems that resulted in higher numbers of electronically monitored employees (Alge \& Hansen, 2013; Ravid et al., 2019). For example, in algorithmic management an algorithm distributes tasks, regulates work processes, and controls performance. This management style is more and more widespread in technology corporations and cannot work without collecting data on employees' behavior (Galière, 2020; Möhlmann \& Zalmanson, 2017). This way, monitoring is present in a greater intensity and extent than previously seen.

Whereas proponents of electronic monitoring stress advantages like fair performance evaluation, improved security of employees, and higher accountability, opponents emphasize disadvantages like reduced employees' well-being (Ball, 2010; Ravid et al., 2019; Sewell \& Barker, 2006; Yost et al., 2018). Research on electronic monitoring reflects these different stances: Some studies find detrimental effects not only on employees (Ball \& Margulis, 2011; Cascio \& Montealegre, 2016; Ravid et al., 2019; Stanton, 2000; Yost et al., 2018), but also on supervisors and organizations (Reilly, 2010; Yost et al., 2018); according to other studies, electronic monitoring increases well-being, performance, and job satisfaction, especially if used in a developmental and supporting manner (Ravid et al., 2019; Wells et al., 2007). The increasing use and intensity as well as these different effects of electronic monitoring make a quantitative and systematic research synthesis desirable.

So far, there have been two systematic meta analyses on electronic monitoring and its impact on employees (Backhaus, 2019; Carroll, 2008) and both have major limitations. The meta-analysis of Carroll (2008) was only concerned with feedback interventions and does not differentiate between studies with and without electronic monitoring. Although Backhaus (2019) focused specifically on electronic monitoring, he did not investigate moderators except of study design. In addition, many studies in this field report multiple effect sizes for the same outcome what makes it necessary to reflect this in the analysis. Thus, the current 
meta-analysis updates and extends the previous meta-analysis.

\section{Background}

\section{Definition and Use of Electronic Monitoring}

One of the first studies on electronic monitoring defined it "as the use of electronic instruments or devices such as audio, video, and computer systems to collect, store, analyze, and report individual or group actions or performance” (Nebeker \& Tatum, 1993, p. 509). Though technical advances have tremendously changed the methods how employees can be monitored (Cascio \& Montealegre, 2016; Khakurel et al., 2018) since Nebeker and Tatum's (1993) study, the purpose and target have not changed: employees' performance and behavior are monitored to maintain organizations' performance, prevent theft and legal liabilities, and foster security or development of employees (Ball, 2010; Ravid et al., 2019). In line with these reasons, previous research has often seen monitoring either as a stress inducing factor for employees or a possibility to ensure security and performance of employees by organizations (Sewell \& Barker, 2006).

The latest representative survey on the use of electronic monitoring is from the American Management Association (2007) and estimates that about half of the surveyed companies in the USA are electronically monitoring their employees. Since then, the use of ubiquitous computing has proliferated. Ubiquitous computing describes the application of computing devices in any form and location. Examples are wearables and IoT (internet of things) devices. Wearables are small devices worn by individuals that are capable of collecting a large amount of data about their wearer (see also Khakurel et al., 2018). IoT describes a concept to connect a vast number of devices sharing the data of their sensors. Furthermore, advances in big data analysis, and reduced costs has further increased the use of monitoring systems (Cascio \& Montealegre, 2016; Ghislieri et al., 2018; Schwarzmüller et al., 2018). Compared to traditional human monitoring, electronic monitoring offers the possibility to continuously and unobtrusively collect and store data on employees' behavior (Ravid et al., 2019). For example, modern workforce management systems can analyze vast amounts of data to identify how much time employees spent in meetings or on the phone and which 
employees are influential to others (e.g., Microsoft, 2019).

\section{Effects of Electronic Monitoring on Employees}

Previous studies addressed the impact of electronic monitoring on an array of dependent variables like work satisfaction, perceived stress, privacy violation, performance, perceived autonomy, trust, social support, and alike (Alge \& Hansen, 2013; Backhaus, 2019; Ravid et al., 2019; Stanton, 2000). Thus, it is possible to examine a huge number of effects which electronic monitoring may have on employees. At this point, we focus our efforts on job satisfaction, stress, and performance because there is a large number of studies that took these variables into account, whereas other variables were less often addressed (Backhaus, 2019). In addition, these other possible dependent variables show a substantial correlation with our main outcomes. For example, a meta-analysis found high relationships between job satisfaction, justice / fairness perceptions, and citizenship behaviors (Fassina et al., 2008). In addition, the three chosen variables show distinct characteristics: job satisfaction can show the impact of electronic monitoring on employees' work attitudes, stress can show the impact on employees' well-being, and performance is a major justification for the implementation of electronic monitoring.

\section{Fob Satisfaction and Stress}

There are different justifications to monitor employees electronically. Ball (2010) states three different reasons: maintaining productivity and resources of an organization, protection of corporate interests and secrets, and protection from legal liabilities. Some researchers extend this list of purposes by monitoring techniques that are targeted employees' security and development (Ravid et al., 2019; Sewell \& Barker, 2006). For example, a location sensing device can be used to track employees during their work time, but can also solely be used to locate employees after an accident. Taking these different purposes and their frequency into account (see, American Management Association, 2007; Deutscher Gewerkschafts Bund, 2016; Holland et al., 2015, for older data on monitoring use), most monitoring implementations are targeted at employees' behavior to ensure productivity and corporate interests. These organizational interests might not be completely in line with 
employees' interests (Frey, 1993). This way, electronic monitoring might not only affect employees' performance but also the perception of job satisfaction and stress.

Job satisfaction describes the contentedness of an individual with their job or certain facets of their job (Neuberger et al., 1978). There are different theoretical justifications why electronic monitoring may affect employees' job satisfaction. For example, Holman et al. (2002) argues from a stress stance that the intensity of monitoring will reduce job satisfaction due to higher perceived work pressure. Others propose a relationship with work design (Parker, 2014): Working procedures that have less variety and complexity are more easily to observe and monitor but reduce employees' autonomy (Carayon, 1994; Gagné \& Bhave, 2011; Martin et al., 2016). This in turn reduces job satisfaction. Empirically, several studies found a negative relationship of electronic monitoring with job satisfaction (cf., Alge \& Hansen, 2013; Backhaus, 2019; Ravid et al., 2019). Based on these theoretical arguments and empirical findings, we propose the following hypotheses:

Hypothesis 1: There is a negative relationship between electronic monitoring and employees' job satisfaction

Compared to job satisfaction, similar conclusions can be drawn to perceived stress of employees. According to Karasek (1979), perceived stress is an energized state caused by work demands, conflicts, and stress resulting from other life domains. If this energy cannot be released due to low autonomy it manifest into strain and harms the individual in the long-term. Again, if monitoring reduces the autonomy of employees and emphasizes performance measures, it will probably increase stress. This relationship has been found empirically (cf., Alge \& Hansen, 2013; Backhaus, 2019; Ravid et al., 2019). Thus, we propose the following hypothesis:

Hypothesis 2: There is a positive relationship between electronic monitoring and employees' perceived stress.

In addition to these main effects, there are plausible moderators that may alter the relationship of monitoring with job satisfaction and stress. As Ravid et al. (2019) pointed out, monitoring "is not a psychological construct but a method" (Ravid et al., 2019, p. 102) and its effects may thus differ according to its characteristics. One of these characteristics is the 
purpose that is communicated to employees why they are monitored. So far, the most attention in monitoring research gained performance maintenance and employee development (DelVecchio et al., 2013; Ravid et al., 2019; Wells et al., 2007). Whereas performance maintenance is in line with organizational interests, employee development is in line with employees' interests. For example, monitoring the number of pieces of blue-collar workers might have the reason to maintain employees' performance by the management, but could also solely provide feedback to employees. The influence of purpose on the relationship of monitoring with job satisfaction and stress can be explained using attributional theories (e.g., Nishii et al., 2008). If employees perceive electronic monitoring in their interests, the impact of monitoring on stress and job satisfaction should be less severe than they perceive monitoring only in organizational interests. Thus, we propose the following hypotheses:

Hypothesis 3: There is a stronger negative relationship of electronic monitoring with job satisfaction if monitoring is in organizational interests than in employees' interests.

Hypothesis 4: There is a stronger positive relationship of electronic monitoring with stress if monitoring is in organizational interests than in employees' interests.

Beyond the purpose of monitoring, Nebeker and Tatum (1993) and Gosnell et al. (2020) found evidence for the relevance of performance targets in monitoring research. Despite its impact on productivity, Nebeker and Tatum (1993) argue that performance targets put employee in a threat that they may fail these targets. A failed performance target might be seen as a defeat by employees. Thus, we propose that performance targets increase the negative impacts of electronic monitoring:

Hypothesis 5: There is a stronger negative relationship of electronic monitoring with job satisfaction if monitoring is used together with performance targets than without performance targets.

Hypothesis 6: There is a stronger positive relationship of electronic monitoring with stress if monitoring is used together with performance targets than without performance targets. 


\section{Performance}

A key justification for the use of electronic monitoring is the observation and maintenance of organizational performance and thus employees' performance. Regarding performance, different theories come to different conclusions about the effect of monitoring on employees' performance. Following a stress perspective, electronic monitoring reduces performance in the long term due to the strain an individual experiences (Karasek, 1979). In contrast, agency theory (Eisenhardt, 1989) predicts higher performance in monitored employees than in non-monitored employees (Mahaney \& Lederer, 2011). According to agency theory, the agent (or the employee) has a knowledge advantage over the principal (or the supervisor), because the agent knows which performance they has achieved and is able to achieve. Monitoring balances this advantage by conveying these information to the principal as well. This way, the principal can act according to the agents' performance and maintain

performance (see Frey, 1993, for a critique on this simplification). Indeed, research has found a positive impact of electronic monitoring (e.g., Nebeker \& Tatum, 1993; Huston et al., 1993) as well as a negative impact of monitoring on performance (e.g.; Aiello \& Kolb, 1995; Becker $\&$ Marique, 2014). To summarize, there are different propositions regarding performance though the previous meta analysis by Backhaus (2019) found a positive relationship between electronic monitoring and performance. We follow this finding and propose a positive relationship between these two variables:

Hypothesis 7: There is a positive relationship between electronic monitoring and employees' performance.

\section{Study Setting as a Moderator}

A long debated topic in social sciences is the generalizability of results in laboratory studies to real world settings (e.g., Mitchell, 2012). This issue is prevalent in the field of electronic monitoring research as well (Ravid et al., 2019). For example, Becker and Marique (2014) asked undergraduates to put wooden pegs in a box for five minutes. Whether the findings of this study is transferable to a long-term employment relationship while being monitored is questionable. However, even field studies in monitoring research were most 
likely concentrated in call-centers where work is highly standardized and monitored (Ravid et al., 2019). To conclude, it is possible that laboratory studies report different effect sizes than field studies due to short-term effects and missing relevance for the future working conditions. At the contrary, several meta-analysis on this topic suggest that laboratory studies are comparable to studies in the field especially in work and organizational psychology and if workplace characteristics are examined (Mitchell, 2012; Vanhove \& Harms, 2015). Thus, there is conflicting evidence regarding the generalizability of laboratory studies to field settings. We propose the following research question without any assumption of the direction of an effect:

Research Question 1: Do laboratory studies and field studies differ in the magnitude of their effect size?

\section{Method}

Hypotheses, variables, data collection information, and analyses were registered prior to conducting this study. In addition, this paper was written as a reproducible manuscript using R (see Aust \& Barth, 2018). All files to reproduce statistical analysis and reports of statistics will be publicly available. The preregistration and the analysis files are available at the Open Science Framework (https://osf.io/q57v8/?view_only=32b5a6d8e4db4d78a611849459bcf06c). The preregistration states more moderation hypotheses than reported in this study, but we could not investigate these hypotheses as too few studies differ in these moderators.

\section{Literature Search}

To identify published articles we conducted an extensive literature search using several databases and sources. We gathered articles from the Web of Science database and the EBSCO Information Services. The following databases were included in the search on EBSCO Information Services: Academic Search Complete, APA PsycArticles, APA PsycInfo, and Psyndex. In contrast to our preregistration, we decided to widen our literature search. Thus, we also included results from ACM Digital Library, IEEExplore, and AISeLibrary. In addition, we added the following databases to the EBSCO Information Services: ERIC, EconLit, OpenDissertations, and Business Source Premier. In these databases, combinations and 
Table 1

Used Search Terms to Gather Articles From

Databases

\begin{tabular}{lll}
\hline work & electronic & monitoring \\
job & performance & surveillance \\
employ & computer & observation \\
occupation & smartphone & \\
& smartwatch & \\
& tablet & \\
& wearables & \\
& iot \\
\hline
\end{tabular}

Note. Terms in columns were linked with

"or" operators, terms between columns

were linked with "and" operators. See

supplemental material on the Open Science

Framework for more information.

alterations of words related to work and electronic monitoring were used as search terms (see Table 1 for more details). However, search terms varied slightly between the databases due to different features (see the supplemental material on the Open Science Framework for the corresponding search terms to each database). We conducted the search on February, 3th and 4th, 2021.

Initially, we gathered 8961 studies. After removing duplicates (8301 studies remained), we applied our inclusion and exclusion criteria (see below) first to titles and then to abstracts (190 studies remained). After that, we conducted a backward and forward search on the remaining articles and checked SIOP proceedings. In addition, we reached out to researchers who published more than two articles in the field to ask for overlooked or unpublished studies. Overall, we asked 47 researchers and got replies from 16 researchers. Finally, 247 studies were eligible for full text assessment. Found, included, and excluded studies are 


\section{Figure 1}

Flowchart Showing The Process of Identifying and Selecting Studies

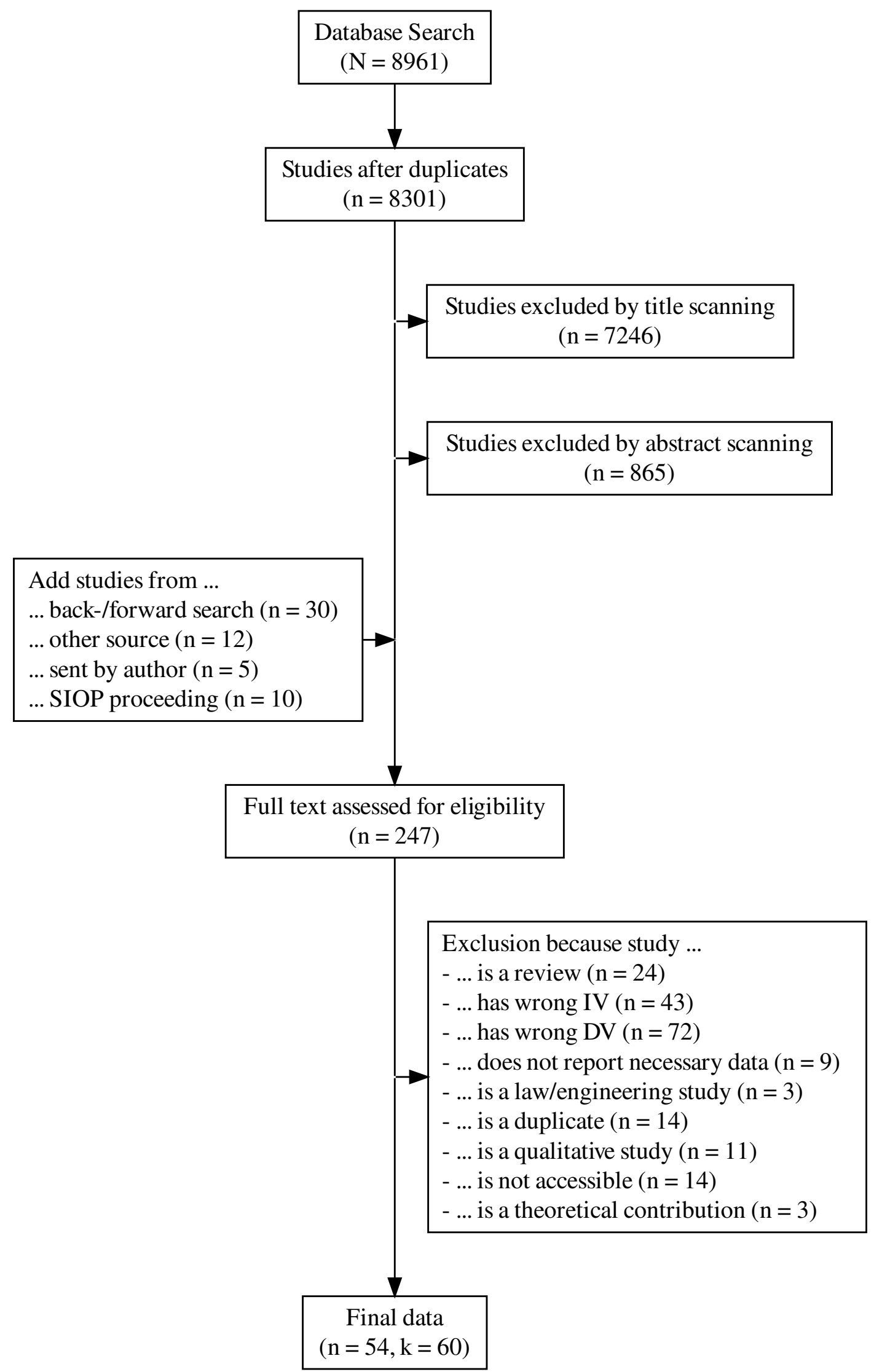


depicted in Figure 1.

\section{Inclusion and Exclusion Criteria}

To be included in our current meta-analysis, studies had to meet the following criteria: They (a) had to be an empirical study, (b) must be written in English or German language, (c) had to implement electronically or computer-based monitoring in a working context, and (d) had to contain at least one of the relevant dependent variables (job satisfaction, stress, and/or performance). In addition, studies had to be full-text accessible. Studies were excluded if they were a literature review, merely stated ethical or moral perspectives, monitoring was realized by direct/personal monitoring without electronic tools, or none of the relevant dependent variables were present (see also Figure 1). When preregistering the current study, we were not aware of the number of studies that are concerned with electronic monitoring of hand hygiene in a clinical context (e.g., Iversen et al., 2020). Although these studies fitted the inclusion criteria, we excluded them because hand hygiene is a single, well defined behavior compared to performance that consists of multiple facets.

\section{Final Data Set and Coding of Studies}

All studies that were deemed eligible for full text assessment were assessed by two raters (inter-rater reliability $=94.4 \%$ ). All coders used the same coding table, which ensured an identical coding procedure. Beforehand, coders were instructed to make sure that all coding variables were understood and all coders had a common ground of coding variables. All independent, dependent, and moderator variables were coded. If the studies did not report necessary details, we reached to the authors to obtain them. In five cases it was not possible to obtain standard deviations for reported means. We imputed these standard deviations using a similar approach to Kwon and Reis (2015). We predicted the missing standard deviations by a Bayesian generalized linear model (assuming a Gamma-distribution of the standard deviations) from the corresponding means $\left(R^{2}=0.50,95 \% \mathrm{CI}[0.36,0.66]\right)$. Due to the low number of missing values and for the sake of easier reporting, we refrain from reporting results of a multiple imputation instead reporting results of a single imputation. However, results did not substantially change on subsequent runs of the imputation model or 
with multiple imputation.

To be included, studies had to manipulate the presence of electronic monitoring (experimental design), compare groups / organizations with and without monitoring (quasi-experimental design), or report a self-report of an electronic monitoring measure (correlative design). In the case of a correlative design, we excluded studies which only reported measures like perceived privacy invasion (e.g., Yost et al., 2018), satisfaction with performance monitoring (e.g., McNall \& Stanton, 2009), or certain characteristics like monitoring purpose (e.g., DelVecchio et al., 2013). Beyond that, studies had to report one of our three dependent variables: job satisfaction, stress, and performance. Job satisfaction was always a self-reported measure and included similar constructs like task satisfaction (e.g., Nebeker \& Tatum, 1993) or facets like intrinsic/extrinsic job satisfaction (e.g., Holman et al., 2002). Stress was most of the times a self-report measure and included constructs like burnout (e.g., Adams \& Mastracci, 2019), work pressure (e.g., Carayon, 1994), exhaustion (e.g., Castanheira \& Chambel, 2010), and cynicism (e.g., Castanheira \& Chambel, 2010). We included also psycho-physiological measures like pulse rate if this was used as a measure of stress (e.g., Henderson et al., 1998). Performance was most of time experimentally measured (like speed or corrected entries; e.g., Bartels \& Nordstrom, 2012) or provided by ratings of call-center agents (e.g., Story \& Castanheira, 2020).

In addition to the independent and dependent variables, potential moderators were also coded. Monitoring purpose included a developmental purpose (monitoring was perceived as beneficial for the employee), a performance maintenance purpose (monitoring was perceived as beneficial for the organization), and no purpose (no purpose was given for the monitoring procedure). We also coded whether studies were conducted in a laboratory setting or a field setting. In almost all cases, laboratory studies had a experimental design and field studies had a quasi-experimental or correlative design. However, there were three exceptions: Galinsky et al. (1995), Gosnell et al. (2020), and Nebeker and Tatum (1993) conducted an experimental study in a field setting. These three studies were treated as field studies. The moderator goal setting reflected whether participants in a study had to reach a certain performance target. 
At this stage, studies were again dropped if they did not meet the inclusion criteria or met exclusion criteria. The final data set consisted of 54 studies with 60 independent samples, and a total of 224 effect sizes. Overall, each independent sample reported $3.73(S D=3.56$, Median $=3)$ effect sizes for $1.37(S D=0.55$, Median $=1)$ dependent variables.

\section{Data Analysis}

All analyses were conducted in R (Version 3.6.3, R Core Team, 2015) using the metafor package (Version 2.4.0, Viechtbauer, 2010). To convert various effect sizes to the Pearson correlation coefficient, we used the esc package (Version 0.5.1, Lüdecke, 2019). Effect sizes were combined using the Fisher Z-transformation and transformed back to report them on the raw correlation scale.

Several coded studies in our meta-analysis did provide several estimates for the same dependent variable (job satisfaction, stress, and performance) or even for multiple dependent variables (see Huston et al., 1993, for example). To take these dependencies between effect sizes coming from the same study into account, we estimated a random-effects model with multiple dependent variables (Viechtbauer, 2010). This allowed us to analyze all studies and all dependent variables within a single analysis. More specific, we extended the regular random effects model (that has two levels) to a three-level model in which effect sizes were nested in dependent variables which in turn where nested in independent samples. Therefore, we estimated for each dependent variable in each independent sample a true effect. This way, we were able to estimate the variance of the effect sizes which originates from differences between studies (Viechtbauer, 2010). For this purpose, we report $\tau$, an estimator for the standard deviation of the true effects between studies. $\tau$ does not differentiate between random or systematic sources of variance. Accordingly, moderators can be used to explain systematic differences between studies and reduce $\tau$. To depict this influence, we report how much variance (in percent) a moderator can explain in between-study variance. For every moderator, a single meta-regression model was estimated.

However, dependencies between effect sizes make it necessary to know the covariance between dependent variables within studies (Kalaian \& Raudenbush, 1996). Unfortunately, 
these covariances are often not available like in our case (Noortgate et al., 2012). To circumvent this issue, we applied two distinct approaches. First, we examined the correlations between job satisfaction, performance, and stress on metaBUS (date of query: March, 24th, 2021; Bosco et al., 2019). metaBus is a research synthesis platform to conduct rudimentary, instant meta-analysis on a large set of collected research articles (see also https://metabus.org/). Job satisfaction (metaBUS ID: 20072) correlated with stress (metaBUS ID: 20432) to $r=-.29$ and with performance (metaBUS ID: 40055) to $r=.19$. Stress correlated with performance to $r=.01$. We used this information to impute the missing covariances between effect sizes within the same independent sample. For effect sizes of the same dependent variable, we assumed a correlation of $r=.50$ (cf., Scammacca et al., 2014). We assumed no correlation between effect sizes of different samples. To impute these information, the clubSandwich R package was used (Version 0.5.3, Pustejovsky, 2021). Finally, we used a cluster robust estimation of the variance-covariance matrix to report confidence intervals (Viechtbauer, 2010). This is an additional method to take dependency between effect sizes into account. Please note that the reported results did not differ substantially from results without an imputed covariance matrix and without a robust estimation. To show possible biases in the main meta-analytical results, we created a funnel plot (see Figure 3).

\section{Results}

\section{Descriptives of Studies and Samples}

All included studies and their description are shown in Appendix A. In average the samples had an age of $M=27.27(S D=9.13)$ and were to $M=66.5(S D=22.1)$ percent female. The studies were conducted in the United States $(n=35)$, the United Kingdom $(n=4)$, Australia $(n=3)$, Germany $(n=3)$, Canada $(n=1)$, Iceland $(n=1)$, Turkey $(n=1)$, South Africa $(n=1)$, Pakistan $(n=1)$, New Zealand $(n=1)$, and China $(n=1)$. Half of the studies were conducted in or before 2008. The oldest included study was from 1986, and the latest from 2020. 


\section{Main Results}

Hypothesis 1 stated a negative relationship between electronic monitoring and job satisfaction. Indeed, we found a reliable negative relationship between these two variables, $r=-.09,95 \% \mathrm{CI}[-.15,-.03]$. Hypothesis 2 proposed a positive relationship of electronic monitoring with stress which we found as well, $r=.12,95 \% \mathrm{CI}[.07, .18]$. However, we did not find the positive relationship of monitoring with performance as stated in Hypothesis 7, $r=-.01,95 \%$ CI $[-.06, .04]$. Thus, our hypotheses regarding main effects can be accepted in the case of job satisfaction (Hypothesis 1) and stress (Hypothesis 2) but not in the case of performance (Hypothesis 7). Main meta analytical results are shown in Table 2 and Figure 2. A funnel plot is shown in Figure 3. 


\section{Figure 2}

A Forest Plot Showing Included Studies

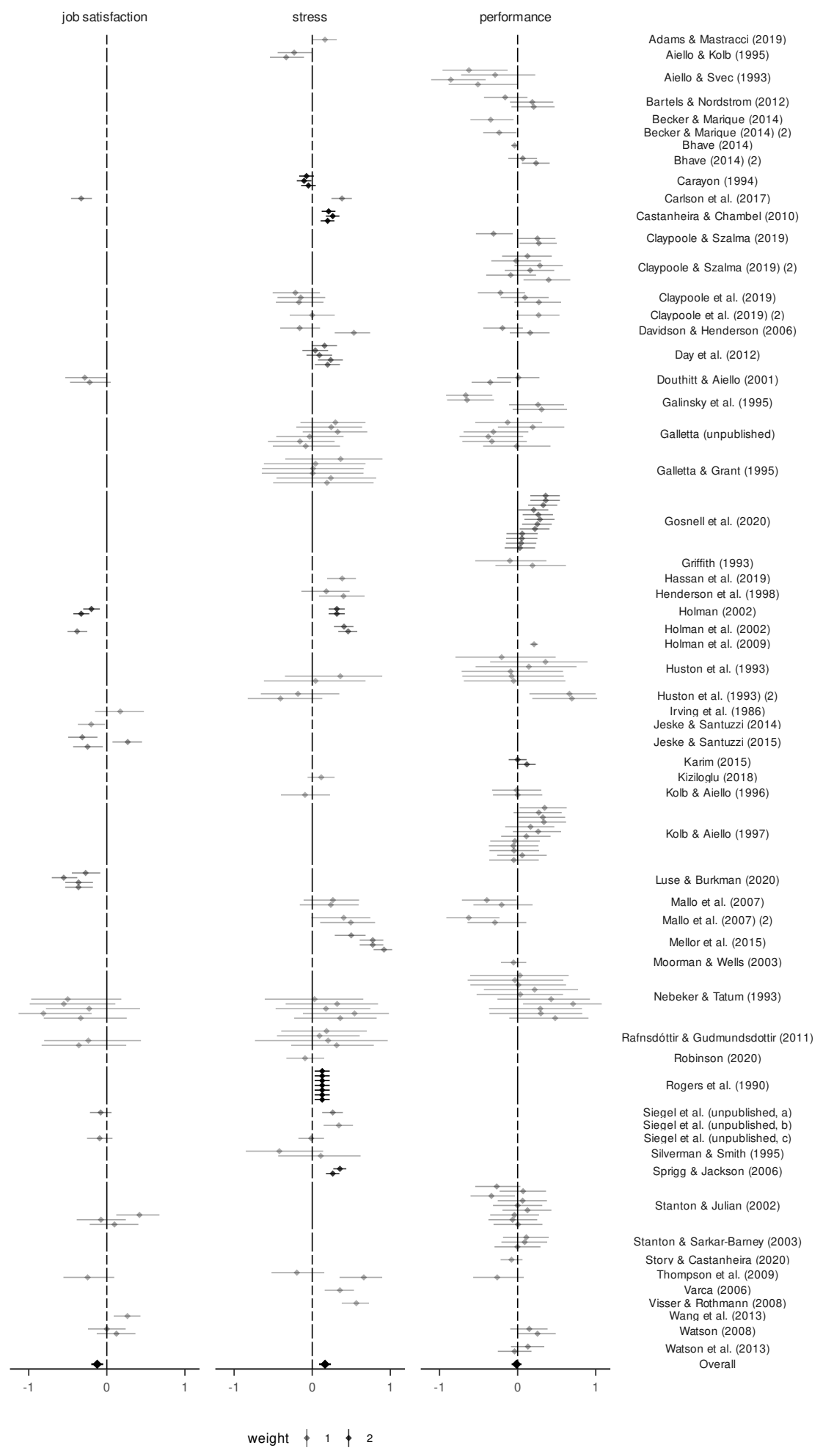

Note. Included studies, their effect sizes and the overall effect size for job satisfaction, stress, and performance (including the 95\% CI) are shown. Opacity indicates the weight (in percent) of an effect size in the meta-analytical model. 
Figure 3

Funnel Plots for Job Satisfaction, Stress, and Performance

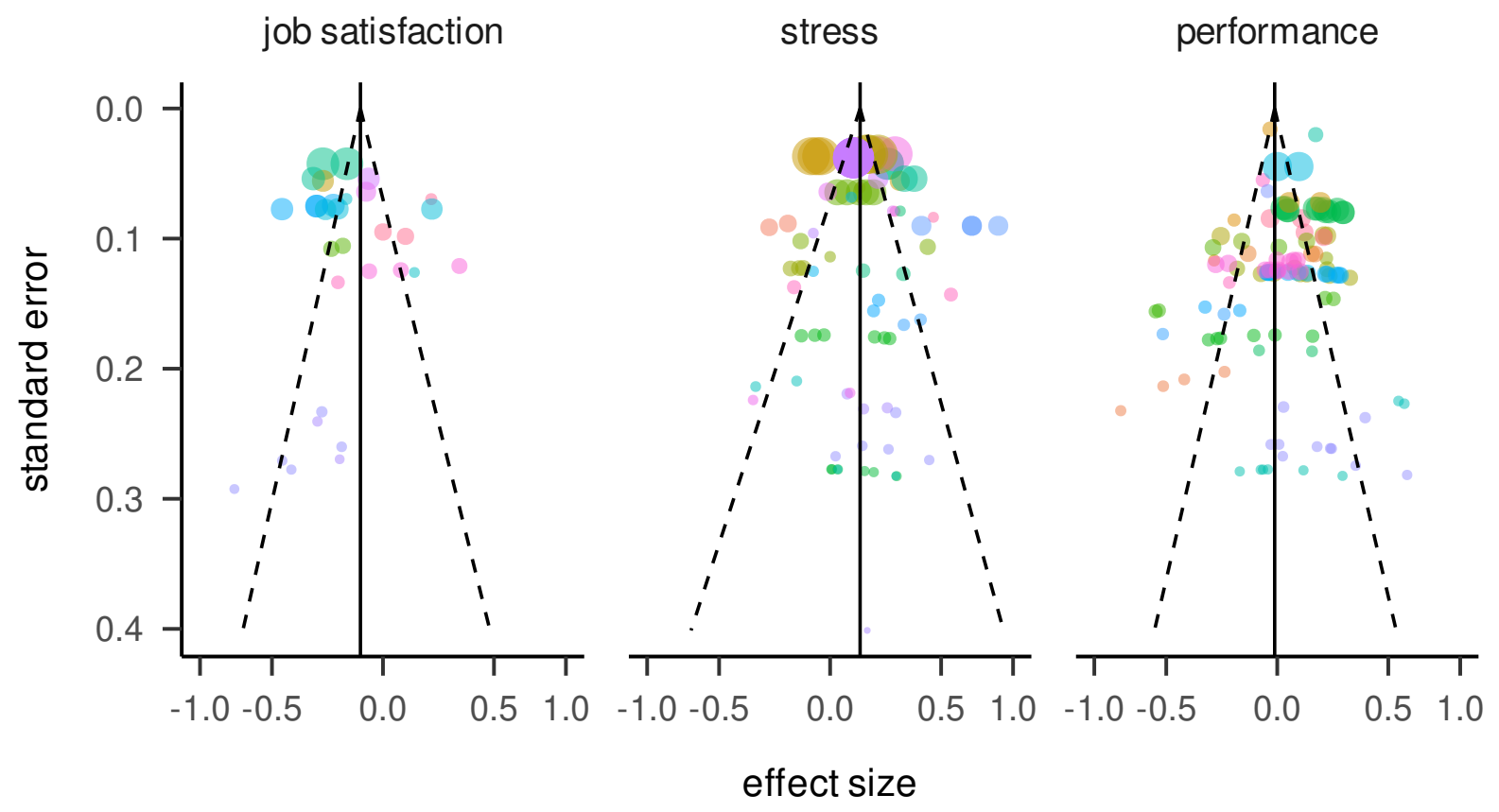

weight 2

Note. Dots indicate a single effect size with its corresponding standard error. Dot size represent the weight (in percent) in the meta-analytical model. Colors indicate independent samples. 


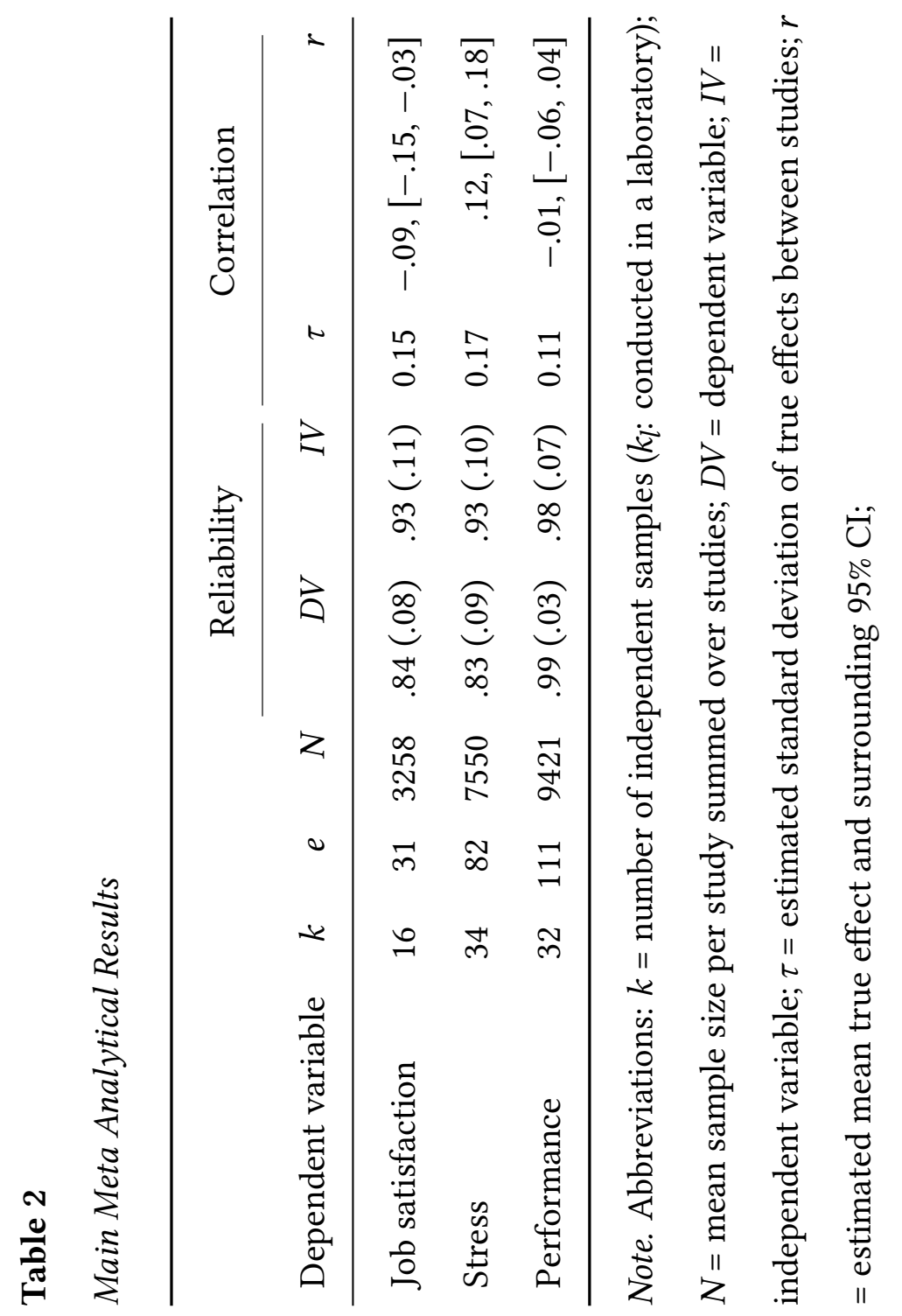




\section{Effects of Moderators}

Hypothesis 3 stated that monitoring has a stronger negative relationship with job satisfaction if monitoring emphasizes organizational interests than employees' interests, and Hypothesis 4 stated that monitoring has a stronger positive relationship with stress in the case of emphasizing organizational interests. There were too few studies to examine the impact of developmental purposes, but we were able to contrast organizational interests against no given purposes. No given purposes yielded a stronger negative relationship with job satisfaction, $r=-.14,95 \% \mathrm{CI}[-.25,-.03]$, than with performance maintenance purposes, $r=-.07,95 \% \mathrm{CI}[-.22, .07]$. However, CIs overlapped strongly, so there is no strong support for a differentiation of these two attributions. This was similar in the case of stress. No given purpose, $r=.02,95 \% \mathrm{CI}[-.11, .16]$, overlapped strongly with performance purposes, $r=.09$, 95\% CI $[-.02, .20]$. On an exploratory basis, we also investigated this moderator for performance. Developmental purposes showed no relationship with performance, $r=.00$, $95 \% \mathrm{CI}[-.17, .17]$, whereas no given purpose showed a slightly positive relationship, $r=.03$, $95 \% \mathrm{CI}[-.05, .10]$, and performance purposes a slightly negative relationship, $r=-.04,95 \%$ CI $[-.12, .05]$. Also in this case were CIs too large and the differences too small to interpret differences between moderator levels (see Table 3). 


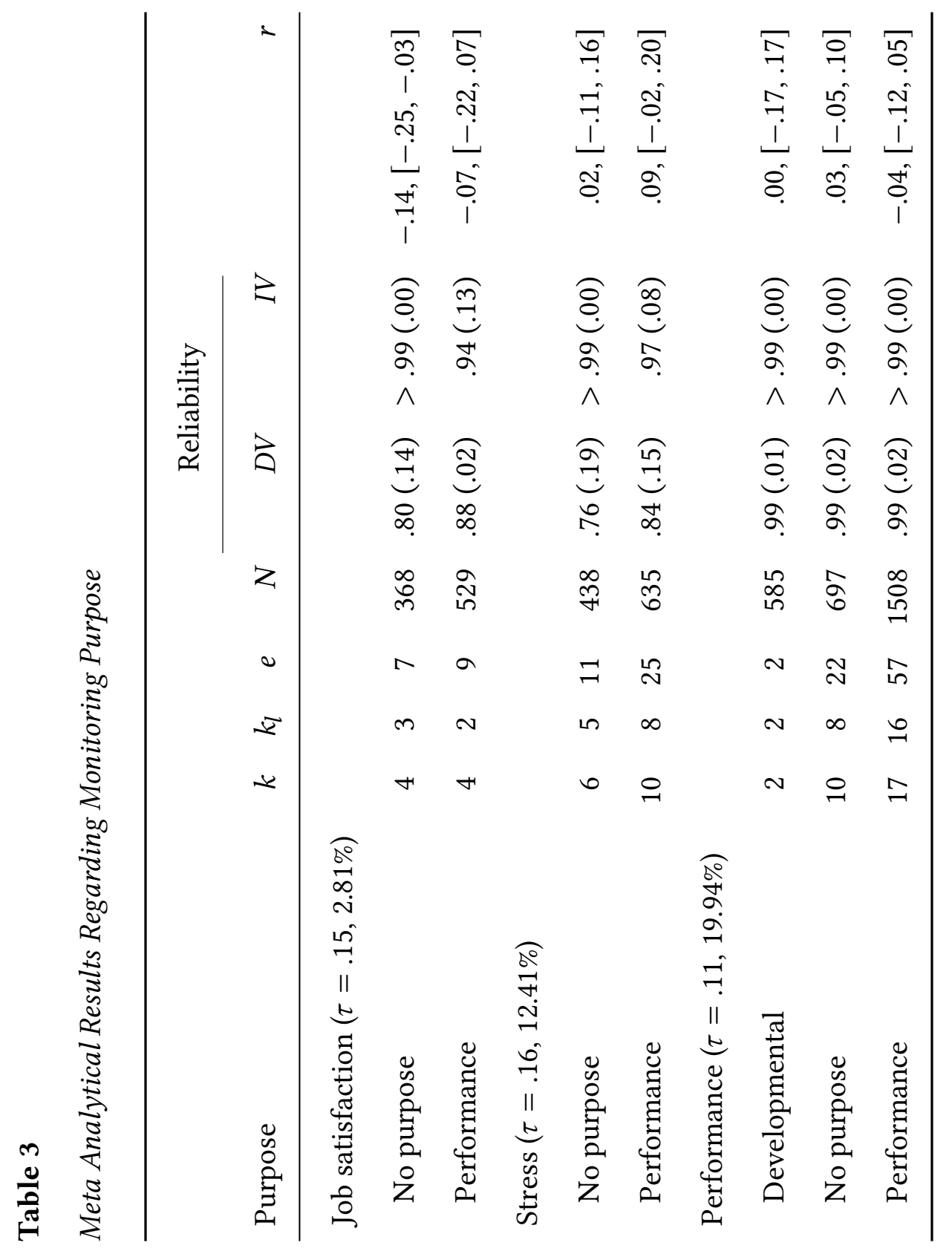




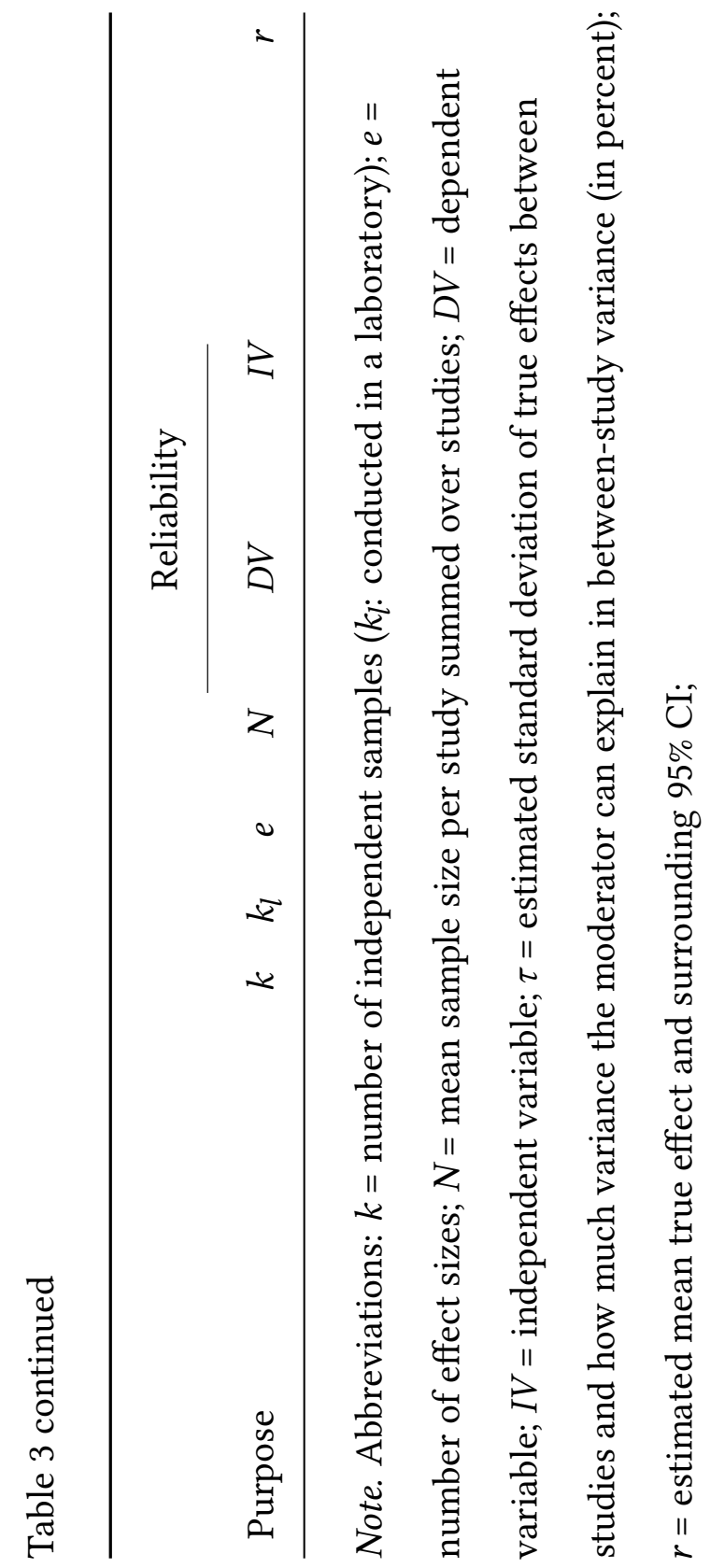


Hypothesis 5 and 6 were concerned with the effect of performance targets on the relationship of monitoring with job satisfaction and stress. In both cases, the existence of performance targets should strengthen the relationship of monitoring with the dependent variable. Regarding job satisfaction, performance targets yielded a stable negative relationship, $r=-.20,95 \% \mathrm{CI}[-.34,-.04]$, whereas this was not the case for the absence of performance targets, $r=.00,95 \% \mathrm{CI}[-.16, .15]$. Thus, there is evidence in favor of Hypothesis 5. The relationship with stress was with and without performance targets slightly positive but not differentiable between each other, $r=.08,95 \%$ CI $[-.09, .26]$ and $r=.04,95 \%$ CI $[-.06, .13]$ respectively. Thus, there was no conclusive evidence in favor of or against Hypothesis 6. On an exploratory basis, we tested this moderator for performance. There was no relationship with performance targets, $r=.03,95 \% \mathrm{CI}[-.03, .09]$, and without performance targets, $r=-.01,95 \% \mathrm{CI}[-.08, .05]$. See Table 4 for more information. 


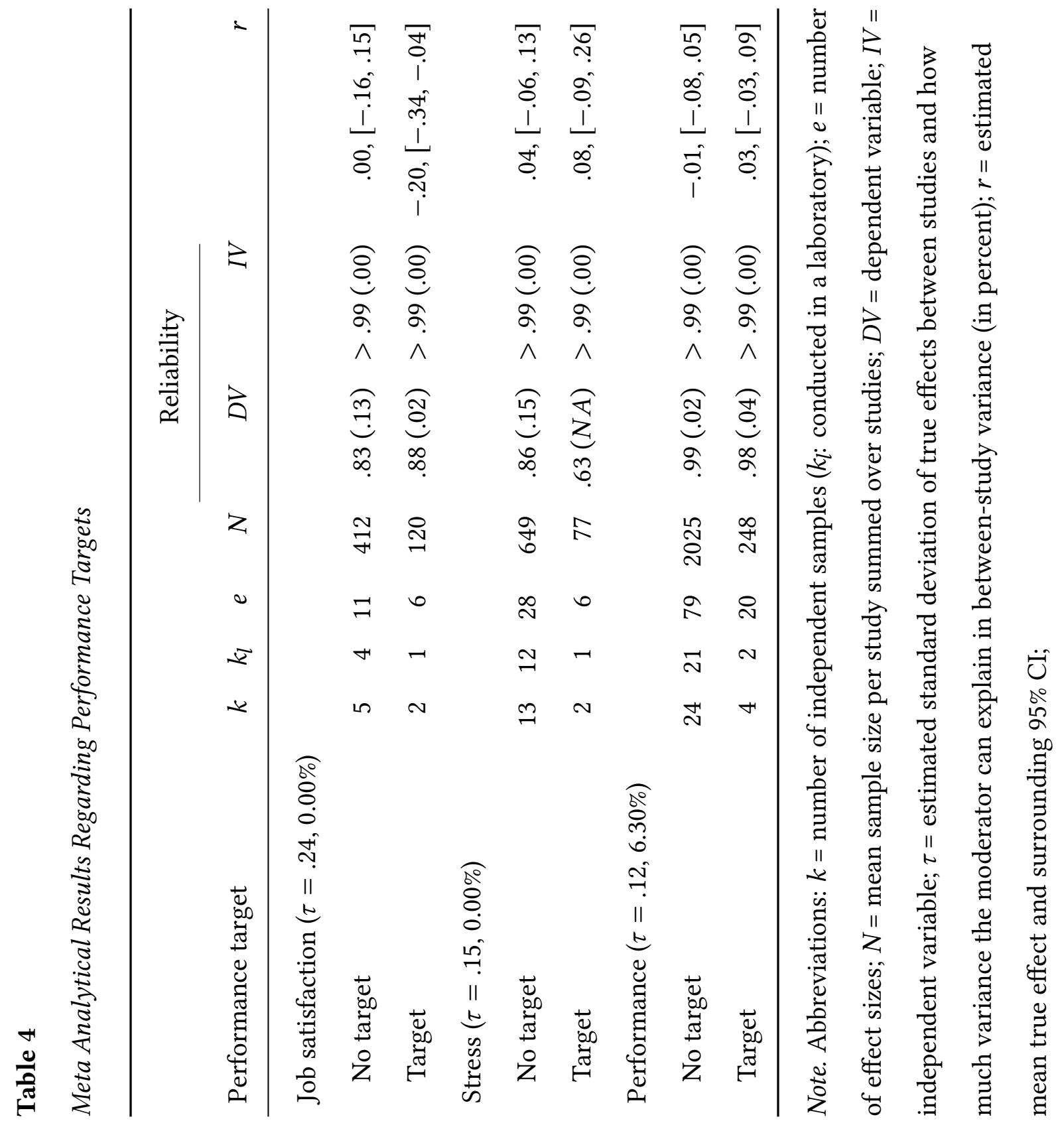




\section{Moderator Study Setting}

Study setting (laboratory vs. field) had a differential influence on the dependent variables. Regarding job satisfaction, a reliable negative relationship was found in field studies, $r=-.13,95 \%$ CI $[-.21,-.06]$, but not in laboratory studies, $r=-.07,95 \%$ CI [-.19, .06]. However, confidence intervals did not indicate a strong difference between these to study settings. Laboratory settings found a correlation of $r=.04,95 \%$ CI $[-.04, .13]$, between stress and monitoring, whereas field studies found a correlation of $r=.18,95 \%$ CI [.10, .25], between these two variables. Thus, Laboratory studies underestimate the relationship of monitoring and stress compared to field studies. In the case of performance, laboratory settings did not find a correlation between monitoring and performance, $r=-.02,95 \% \mathrm{CI}$ $[-.09, .04]$, but field studies found a small relationship, $r=.06,95 \%$ CI $[-.02, .14]$. Therefore, there is small evidence that field studies might find a small positive relationship with performance (see Table 5). 


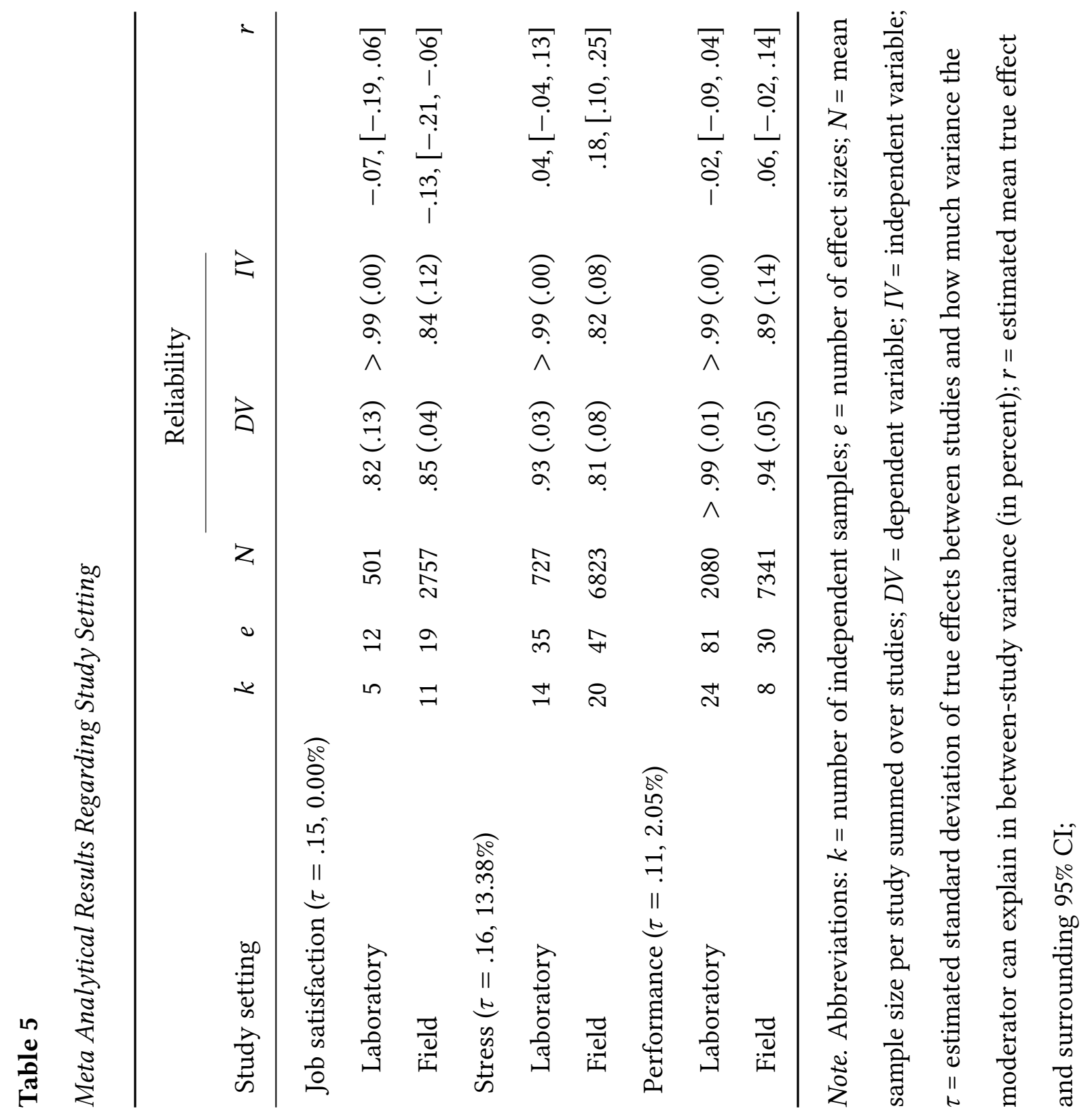




\section{Exploratory Analysis}

On an exploratory basis we were able to investigate two further moderators. In the case of performance, we could distinguish quantity and quality. However, there was no difference between these two kinds of performance (quality: $r=.00,95 \% \mathrm{CI}[-.11, .11]$, quantity: $r=.00,95 \% \mathrm{CI}[-.08, .08]$; see Table 6$)$. In addition, we examined whether feedback of the monitoring system has an impact on the dependent variables. The relationship between monitoring and job satisfaction was lower in the case of feedback, $r=-.29,95 \%$ CI $[-.37$, $-.21]$, than without feedback, $r=-.07,95 \%$ CI $[-.21, .07]$. Also, the relationship with stress was stronger with feedback, $r=.28,95 \% \mathrm{CI}[.23, .33]$, than without feedback, $r=.02,95 \% \mathrm{CI}$ $[-.08, .12]$. In the case of performance, studies in which the monitoring system provided feedback reported a relationship of performance with monitoring, $r=.05,95 \%$ CI $[.00, .10]$. Without feedback there was no relationship, $r=-.01$, 95\% CI [-.08, .05] (see Table 7). 


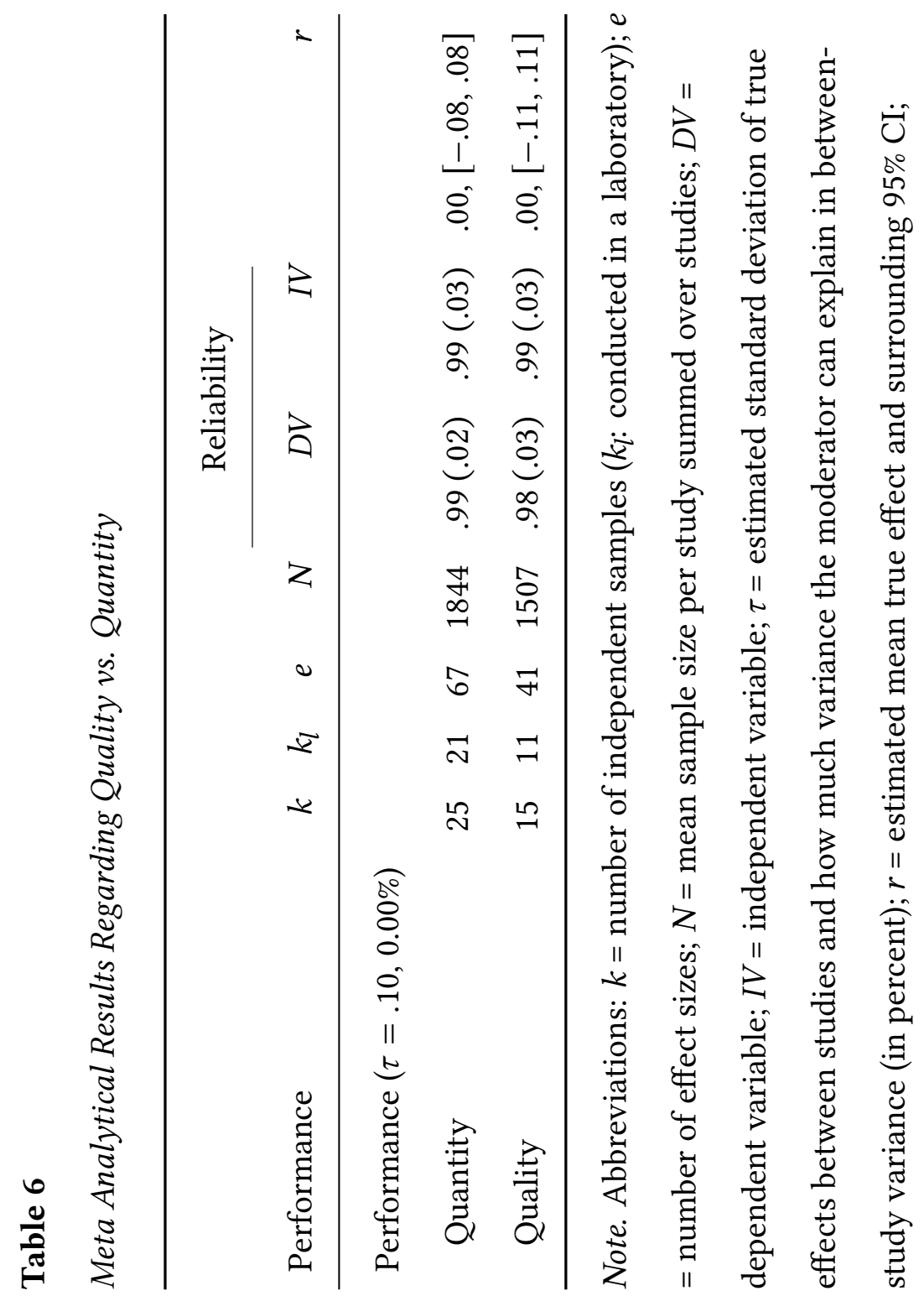




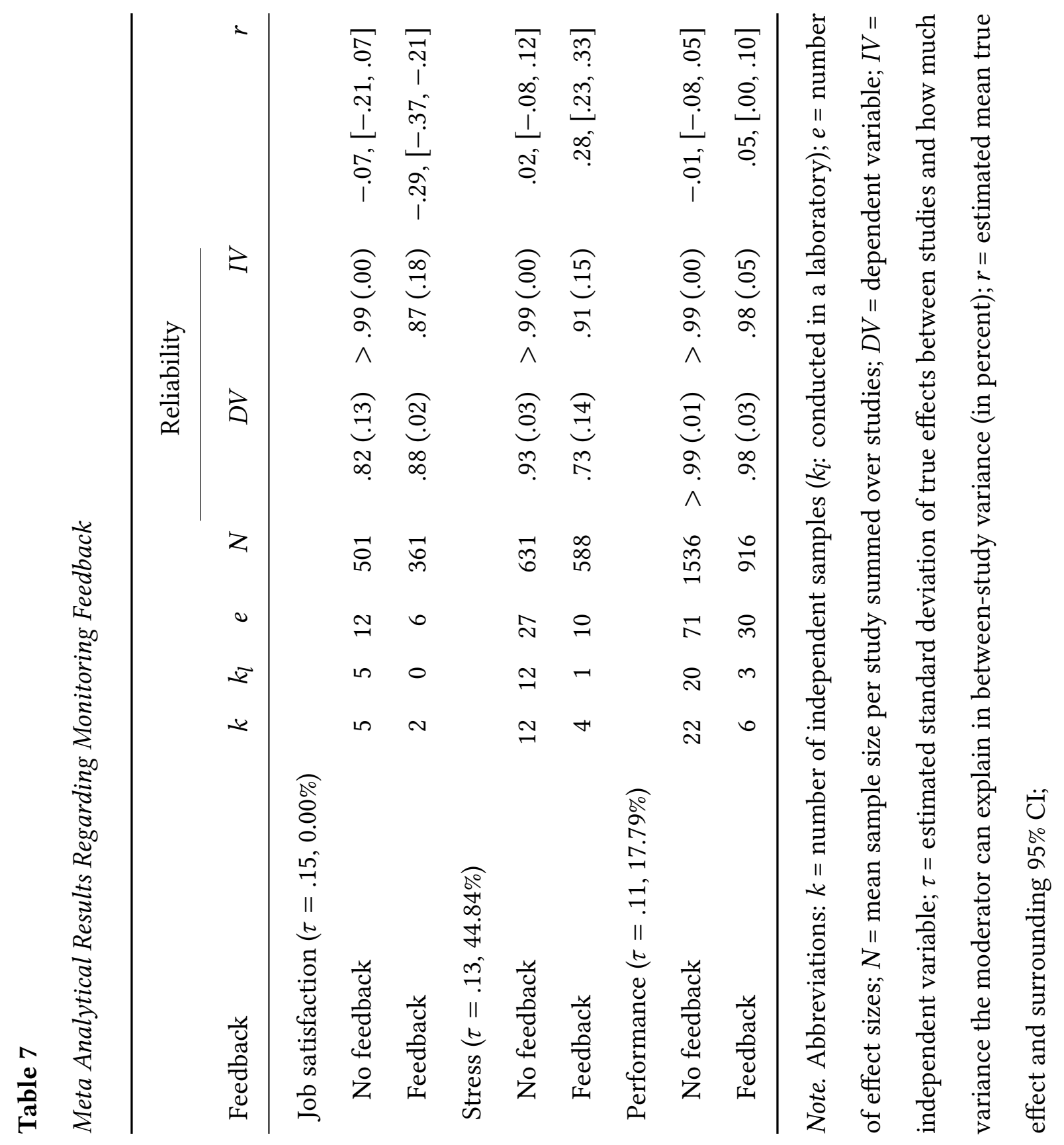




\section{Discussion}

This meta analysis investigated the relationship of electronic monitoring with job satisfaction, stress, and performance. In the current study, we found a reliable negative relationship of monitoring with job satisfaction and a reliable positive relationship with stress. The overall effect size for the influence of electronic monitoring on job satisfaction, $r=-.09$, $95 \%$ CI $[-.15,-.03]$, and on stress, $r=.12,95 \%$ CI $[.07, .18]$, are negligible to small according to Cohen (1988) and Funder and Ozer (2019). The current results (a) support previous findings on the relationship of electronic monitoring with job satisfaction and stress (Backhaus, 2019; Ravid et al., 2019), (b) is in line with stress theories and their predictions (Gagné \& Bhave, 2011; Karasek, 1979; Martin et al., 2016), and (c) supports the notion that electronic monitoring has a negative impact on employees' well-being (Alge \& Hansen, 2013; Ball, 2010; Ravid et al., 2019).

On a first glimpse, one might argue that these effect sizes are too small to be practically relevant. However, it should be kept in mind that a large number of employees may experience electronic monitoring over multiple hours per day for many years in their life. The long-term implications of these small effect sizes have probably severe and aversive consequences for employees' life and well-being (see Bosco et al., 2015; Funder \& Ozer, 2019, for an in-depth discussion). The common language effect size is an indicator for the probability that a score from one group is greater than from another group. In our case, a correlation coefficient of 0.10 corresponds to a common language effect size of $55.65 \%$. If there is no effect, both groups do overlap and the probability is $50 \%$. Thus, if we take electronic monitoring as a binary decision, an employee which is under electronic observation reports more stress and less job satisfaction with a probability of $55.65 \%$. Again, this $5.65 \%$ increase seems small but with the culmination of the number of employees and time, monitoring can have severe impacts. Thus, we would like to stress the importance of these "small" relationships.

If taking moderators into account, there was some evidence that a performance maintenance purpose and performance targets decrease reported job satisfaction of employees. These findings seem to be reasonable as performance maintenance purposes and 
performance targets increase work demands and do not foster employees' resources what should result in decreased job satisfaction (Demerouti et al., 2001; Karasek, 1979). If this explanation is correct, stress should show similar patterns across moderator levels. Even there were some small differences between moderator levels regarding stress, they were far too small to be robust. Feedback seems to be another moderator variable that affects the impact of electronic monitoring. In both cases, job satisfaction and stress, showed a stronger relationship with feedback than without feedback. In leadership research, appropriate feedback is a key variable to foster trust and development of subordinates (see Sexton et al., 2017, for example). However, in research on electronic monitoring, the opposite seems to be the case. A possible explanation is that feedback from monitoring systems is not helping in achieving a goal but to merely signal the amount of work that has to be done. This is a new insight in the area of electronic monitoring and needs further research. Beyond that, laboratory studies seem to slightly underestimate the relationship of electronic monitoring with job satisfaction and stress what might be due to the relevance and long-term implications of a real employment situation.

However, we found no relationship of monitoring with performance and its confidence interval was narrow around zero. Thus, there is most probably no effect of electronic monitoring on performance. This overall effect is in line with stress theories (Karasek, 1979) but in contradiction with agency theory (Eisenhardt, 1989; Mahaney \& Lederer, 2011). Again, we found no great differences when taking moderator levels into account. Comparable to the results regarding job satisfaction and stress, differences were either too small or the uncertainty was too big. However, there seems to be some evidence that performance is higher when feedback is present and in field studies than in laboratory studies. In line with developmental purposes, feedback might be a opportunity for employees to improve their work processes (e.g., in the sense of job crafting, Parker, 2014). However, the exact processes between electronic monitoring, feedback, and performance warrant further research. To conclude, performance maintenance as the most prominent justification for electronic monitoring seems not to be reflected in empirical studies - even if taking the small relationship of monitoring with performance in field studies into account. There might be 
several reasons for not finding this relationship. Electronic monitoring is most often not solely implemented (cf., Cascio \& Montealegre, 2016; Reilly, 2010) but comes with a variety of HR measures like pay-for-performance and certain work design (Gerhart \& Fang, 2015; Parker, 2014). Current research has most of the time not looked into work design decisions that go in line with electronic monitoring and it is thus unknown how they influence each other. This way, it could be possible that there is only a performance benefit by electronic monitoring if it is accompanied by certain HR measures (cf., Posthuma et al., 2018; Stanton \& Weiss, 2000). In contradiction with this argument is that we could not find a strong impact of moderators onto the relationship of monitoring with performance. What is more, there are several arguments in the literature why monitoring might have a negative impact on performance and overshadow positive effects on performance this way. For example, Stanton and Julian (2002) found that employees focus on monitored aspects of their work and disregard non-monitored aspects. This way, the overall performance might be negatively affected and positive effects canceled out. Reilly (2010) investigated how the management level is affected by electronic monitoring. In their study, supervisors and managers complained about reduced autonomy because they have to fulfill certain figures. This changed leadership to fulfilling numbers disregarding the negative side effects this may have. Again, this change in management may cancel positive effects of monitoring employees.

The current study is the latest and comprehensive meta analysis in the area of electronic monitoring research. For example, Backhaus (2019) included only 9 independent samples regarding job satisfaction, 29 regarding stress and strain, and 18 regarding performance. In addition, the first time moderators beyond study design were examined and we applied a more sophisticated meta-analytical model that incorporated dependencies between single effect sizes. In addition, we applied a more rigid definition of electronic monitoring and did not include studies like Alder et al. (2008) which were concerned with privacy invasion and not monitoring per se. 


\section{Limitations and Research Implications}

Readers of the current study should keep the following limitations in mind. First, we investigated only three dependent variables. However, job satisfaction can be seen as a proxy for other attitudinal variables like work motivation and commitment. Stress might be a proxy for other variables that reflect employees well-being. Thus, the current study investigated three dependent variables that are crucial in understanding the effects of electronic monitoring. Beyond that, it is also possible to focus more strongly on verification of certain theories. Using meta-analytical structured equation modeling (Cheung, 2015), mediation models and more complicated models can be examined to verify the predictions of theories.

Second, most of the incorporated studies were either laboratory studies with undergraduates or conducted in call-centers or with clerical workers. Therefore, there is a lack of different professional backgrounds in primary studies. Future research should extend their samples to employees who have not been studied yet. This can be employees in fields like unskilled labor, healthcare, production, and maintenance. Related to this is the need to take different work designs and HR measures into account. It is largely unknown which HR measure do accompany monitoring implementations and how these are related to each other. There is no research how the decision to implement a monitoring system is met on an organizational level. Thus, it is still unclear under which conditions a monitoring system is implemented. For example, electronic monitoring is most easily implemented with simple, repetitive tasks (Carayon, 1993; Smith et al., 1992). Thus, a field study that is neglecting the influence of work design might be missing crucial aspects of monitored work.

Third, the lion's share of electronic monitoring research is concerned with effects of electronic monitoring on subordinates' job attitudes, well-being, and performance (Alge \& Hansen, 2013). However, the effect of electronic monitoring on organizational management and supervisors' behavior and attitudes is largely unknown. Notable exceptions are Aiello and Svec (1993), Oz et al. (1999), Chen and Ross (2005), and Reilly (2010) that suggest that even the autonomy of supervisors is reduced because they have to act in a way to foster key performance indicators.

Finally, taking the exponential rise in published studies in the fields of work and 
business psychology and computer science into account, it is astonishing that electronic monitoring has not seen this exponential trend (note that half of the studies were conducted in or before 2008). The neglect of the importance of electronic monitoring research in these areas is worrisome. More and more employees are affected by electronic monitoring and trends like algorithmic management cannot exist without invasive employee monitoring (Galière, 2020; Möhlmann \& Zalmanson, 2017). Beyond that, some scholars argue that monitoring is already the default in nowadays technological systems (Johnson et al., 2014) and thus is not a temporal phenomenon but will accompany employees and organizations for a long time. Research has the function to shed light which effects these trends have on employees. Thus, further research is warranted to gather more information on this topic.

\section{Practical Implications}

Practitioners and decision-makers in organizations should keep in mind how they implement and use a monitoring system and which HR measures go in line with electronic monitoring. In addition, there should be special attention what an organization expects from a monitoring system. The current study showed that there is no beneficial influence of electronic monitoring on employees' performance and expectations should be changed into this direction.

\section{References}

Adams, I., \& Mastracci, S. (2019). Police body-worn cameras: Effects on officers' burnout and perceived organizational support. Police Quarterly, 22(1), 5-30. https://doi.org/10.1177/1098611118783987

Aiello, J. R., \& Kolb, K. J. (1995). Electronic performance monitoring and social context: Impact on productivity and stress. Journal of Applied Psychology, 80, 3, 339-353. https://doi.org/10.1037/0021-9010.80.3.339

Aiello, J. R., \& Svec, C. M. (1993). Computer monitoring of work performance: Extending the social facilitation framework to electronic presence. Fournal of Applied Social Psychology, 23(7), 537-548. https://doi.org/10.1111/j.1559-1816.1993.tb01102.x

Alder, G. S., Schminke, M., Noel, T. W., \& Kuenzi, M. (2008). Employee reactions to 
internet monitoring: The moderating role of ethical orientation. Journal of Business Ethics, 80(3), 481. https://doi.org/10.1007/s10551-007-9432-2

Alge, B. J., \& Hansen, S. D. (2013). Workplace monitoring and surveillance research since "1984": A review and agenda. In M. D. Coovert \& L. F. Thompson (Eds.), The psychology of workplace technology (pp. 209-237). Routledge. https://doi.org/10.4324/9780203735565-22

American Management Association. (2007). Electronic monitoring \& surveillance survey. http://www.epolicyinstitute.com/2007-survey-results

Aust, F., \& Barth, M. (2018). papaja: Create APA manuscripts with R Markdown. https://github.com/crsh/papaja

Backhaus, N. (2019). Context sensitive technologies and electronic employee monitoring: A meta-analytic review. In R. Chatila \& E. Yoshida (Eds.), 2019 IEEE/SICE international symposium on system integration (SII) (pp. 548-553). Sorbonne Université. https://doi.org/10.1109/SII.2019.8700354

Ball, K. (2010). Workplace surveillance: An overview. Labor History, 51(1), 87-106. https://doi.org/10.1080/00236561003654776

Ball, K. S., \& Margulis, S. T. (2011). Electronic monitoring and surveillance in call centres: A framework for investigation. New Technology, Work and Employment, 26(2), 113-126. https://doi.org/10.1111/j.1468-005X.2011.00263.x

Bartels, L. K., \& Nordstrom, C. R. (2012). Examining big brother's purpose for using electronic performance monitoring. Performance Improvement Quarterly, 25(2), 65-77. https://doi.org/10.1002/piq.20140

Becker, T. E., \& Marique, G. (2014). Observer effects without demand characteristics: An inductive investigation of video monitoring and performance. Fournal of Business and Psychology, 29(4), 541-553. https://doi.org/10.1007/s10869-013-9338-1

Bhave, D. P. (2014). The invisible eye? Electronic performance monitoring and employee job performance. Personnel Psychology, 67(3), 605-635. https://doi.org/10.1111/peps.12046

Bosco, F. A., Aguinis, H., Singh, K., Field, J. G., \& Pierce, C. A. (2015). Correlational effect size benchmarks. Journal of Applied Psychology, 100(2), 431-449. 
https://doi.org/10.1037/a0038047

Bosco, F. A., Field, J. G., Larsen, K. R., Chang, Y., \& Uggerslev, K. L. (2019). Advancing meta-analysis with knowledge-management platforms: Using metaBUS in psychology. Advances in Methods and Practices in Psychological Science, 3(1), 124-137. https://doi.org/10.1177/2515245919882693

Carayon, P. (1993). Effect of electronic performance monitoring on job design and worker stress: Review of the literature and conceptual model. Human Factors, 35(3), 385-395. https://doi.org/10.1177/001872089303500301

Carayon, P. (1994). Effects of electronic performance monitoring on job design and worker stress: Results of two studies. International fournal of Human-Computer Interaction, 6(2), 177-190. https://doi.org/10.1080/10447319409526089

Carlson, J. R., Carlson, D. S., Zivnuska, S., Harris, R. B., \& Harris, K. J. (2017). Applying the job demands resources model to understand technology as a predictor of turnover intentions. Computers in Human Behavior, 77, 317-325.

https://doi.org/10.1016/j.chb.2017.09.009

Carroll, W. R. (2008). The effects of electronic performance monitoring on performance outcomes: A review and meta-analysis. Employee Rights and Employment Policy Journal, 29-48.

Cascio, W. F., \& Montealegre, R. (2016). How technology is changing work and organizations. Annual Review of Organizational Psychology and Organizational Behavior, 3(1), 349-375. https://doi.org/10.1146/annurev-orgpsych-041015-062352

Castanheira, F., \& Chambel, M. J. (2010). Reducing burnout in call centers through HR practices. Human Resource Management, 49(6), 1047-1065. https://doi.org/10.1002/hrm.20393

Chen, J. V., \& Ross, W. H. (2005). The managerial decision to implement electronic surveillance at work: A research framework. International fournal of Organizational Analysis, 13(3), 244-268. https://doi.org/10.1108/eb029006

Cheung, M. W.-L. (2015). metaSEM: An R package for meta-analysis using structural equation modeling. Frontiers in Psychology, 5, 1521. https://doi.org/10.3389/fpsyg.2014.01521

Claypoole, V. L., Neigel, A. R., Waldfogle, G. E., \& Szalma, J. L. (2019). Evaluative social 
presence can improve vigilance performance, but vigilance is still hard work and is stressful. Journal of Experimental Psychology: Human Perception and Performance, 45(5), 616-627. https://doi.org/10.1037/xhp0000635

Claypoole, V. L., \& Szalma, J. L. (2019). Electronic performance monitoring and sustained attention: Social facilitation for modern applications. Computers in Human Behavior, 94, 25-34. https://doi.org/10.1016/j.chb.2019.01.001

Cohen, J. (1988). Statistical power analysis for the behavioral sciences. Taylor \& Francis. https://doi.org/10.4324/9780203771587

Davidson, R., \& Henderson, R. (2006). Electronic performance monitoring: A laboratory investigation of the influence of monitoring and difficulty on task performance, mood state, and self-reported stress levels. Journal of Applied Social Psychology, 30(5), 906-920. https://doi.org/10.1111/j.1559-1816.2000.tb02502.x

Day, A., Paquet, S., Scott, N., \& Hambley, L. (2012). Perceived information and communication technology (ICT) demands on employee outcomes: The moderating effect of organizational ICT support. Journal of Occupational Health Psychology, 17(4), 473-491. https://doi.org/10.1037/a0029837

DelVecchio, S. K., Deeter-Schmelz, D. R., \& Anselmi, K. (2013). Big Brother or big bother? E-monitoring the salesforce. Fournal of Business \& Industrial Marketing, 28(4), 288-302. https://doi.org/10.1108/08858621311313893

Demerouti, E., Bakker, A. B., Nachreiner, F., \& Schaufeli, W. B. (2001). The job demands-resources model of burnout. fournal of Applied Psychology, 86(3), 499-512. https://doi.org/10.1037/0021-9010.86.3.499

Deutscher Gewerkschafts Bund. (2016). DGB-index gute arbeit. Der report 2016: Themenschwerpunkt: Die digitalisierung der arbeitswelt - eine zwischenbilanz aus der sicht der beschäftigten [Research report]. Institut DGB-Index Gute Arbeit. http://index-gute-arbeit.dgb.de/veroeffentlichungen/jahresreports/++co++76276168-a0fb11e6-8bb8-525400e5a74a

Douthitt, E. A., \& Aiello, J. R. (2001). The role of participation and control in the effects of computer monitoring on fairness perceptions, task satisfaction, and performance. 
Journal of Applied Psychology, 86(5), 867-874. https://doi.org/10.1037/0021-9010.86.5.867

Eisenhardt, K. M. (1989). Agency theory: An assessment and review. Academy of Management Review, 14(1), 57-74. https://doi.org/10.5465/amr.1989.4279003

Fassina, N. E., Jones, D. A., \& Uggerslev, K. L. (2008). Relationship clean-up time: Using meta-analysis and path analysis to clarify relationships among job satisfaction, perceived fairness, and citizenship behaviors. Journal of Management, 34(2), 161-188. https://doi.org/10.1177/0149206307309260

Frey, B. S. (1993). Does monitoring increase work effort? The rivalry with trust and loyalty. Economic Inquiry, 31(4), 663-670. https://doi.org/10.1111/j.1465-7295.1993.tb00897.x

Funder, D. C., \& Ozer, D. J. (2019). Evaluating effect size in psychological research: Sense and nonsense. Advances in Methods and Practices in Psychological Science, 2(2), 156-168. https://doi.org/10.1177/2515245919847202

Gagné, M., \& Bhave, D. (2011). Autonomy in the workplace: An essential ingredient to employee engagement and well-being in every culture. In V. I. Chirkov, R. M. Ryan, \& K. M. Sheldon (Eds.), Human autonomy in cross-cultural context (Vol. 1, pp. 163-187). Springer. https://doi.org/10.1007/978-90-481-9667-8_8

Galière, S. (2020). When food-delivery platform workers consent to algorithmic management: A Foucauldian perspective. New Technology, Work and Employment, 35(3), 357-370. https://doi.org/https://doi.org/10.1111/ntwe.12177

Galinsky, T. L., Schleifer, L. M., \& Pan, C. S. (1995). The influence of performance standards and feedback on speed and accuracy in an electronically monitored data-entry task. International Gournal of Human-Computer Interaction, 7(1), 25-36.

https://doi.org/10.1080/10447319509526108

Galletta, D., \& Grant, R. (1995). Silicon supervisors and stress: Merging new evidence from the field. Accounting, Management and Information Technologies, 5(3-4), 163-183. https://doi.org/10.1016/0959-8022(96)00003-3

Gerhart, B., \& Fang, M. (2015). Pay, intrinsic motivation, extrinsic motivation, performance, and creativity in the workplace: Revisiting long-held beliefs. Annual Review of Organizational Psychology and Organizational Behavior, 2(1), 489-521. 
https://doi.org/10.1146/annurev-orgpsych-032414-111418

Ghislieri, C., Molino, M., \& Cortese, C. G. (2018). Work and organizational psychology looks at the fourth industrial revolution: How to support workers and organizations? Frontiers in Psychology, 9(2365), 1-6. https://doi.org/10.3389/fpsyg.2018.02365

Gosnell, G. K., List, J. A., \& Metcalfe, R. D. (2020). The impact of management practices on employee productivity: A field experiment with airline captains. Fournal of Political Economy, 128(4), 1195-1233. https://doi.org/10.1086/705375

Griffith, T. L. (1993). Monitoring and performance: A comparison of computer and supervisor monitoring. Journal of Applied Social Psychology, 23(7), 549-572. https://doi.org/10.1111/j.1559-1816.1993.tb01103.x

Hassan, W., Shabbir, R., Bashir, M., \& Akram, J. (2019). Electronic surveillance consequences: The dark side of technology at workplace. Pacific Business Review International. https://www.pbr.co.in/2019/March.aspx

Henderson, R., Mahar, D., Saliba, A., Deane, F., \& Napier, R. (1998). Electronic monitoring systems: An examination of physiological activity and task performance within a simulated keystroke security and electronic performance monitoring sytem. International fournal of Human-Computer Studies, 48(2), 143-157. https://doi.org/10.1006/ijhc.1997.0167

Holland, P. J., Cooper, B., \& Hecker, R. (2015). Electronic monitoring and surveillance in the workplace: The effects on trust in management, and the moderating role of occupational type. Personnel Review, 44(1), 161-175. https://doi.org/10.1108/PR-11-2013-0211

Holman, D. (2002). Employee wellbeing in call centres. Human Resource Management Fournal, 12(4), 35-50. https://doi.org/10.1111/j.1748-8583.2002.tb00076.x

Holman, D., Chissick, C., \& Totterdell, P. (2002). The effects of performance monitoring on emotional labor and well-being in call centers. Motivation and Emotion, 26(1), 57-81. https://doi.org/10.1023/A:1015194108376

Holman, D., Frenkel, S., Sørensen, O., \& Wood, S. (2009). Work design variation and outcomes in call centers: Strategic choice and institutional explanations. ILR Review, 62(4), 510-532. https://doi.org/10.1177/001979390906200403

Huston, T. L., Galletta, D. F., \& Huston, J. L. (1993). The effects of computer 
monitoring on employee performance and stress: Results of two experimental studies. Proceedings of the Twenty-Sixth Hawaii International Conference on System Sciences, 4, 568-574. https://doi.org/10.1109/HICSS.1993.284234

Irving, R. H., Higgins, C. A., \& Safayeni, F. R. (1986). Computerized performance monitoring systems: Use and abuse. Communications of the ACM, 29(8), 794-801. https://doi.org/10.1145/6424.6430

Iversen, A.-M., Kavalaris, C. P., Hansen, R., Hansen, M. B., Alexander, R., Kostadinov, K., Holt, J., Kristensen, B., Knudsen, J. D., Møller, J. K., \& Ellermann-Eriksen, S. (2020). Clinical experiences with a new system for automated hand hygiene monitoring: A prospective observational study. American Journal of Infection Control, 48(5), 527-533. https://doi.org/10.1016/j.ajic.2019.09.003

Jeske, D., \& Santuzzi, A. (2014). Part-time workers' responses to electronic performance monitoring. International fournal of Working Conditions, 8, 63-82. http://nrl.northumbria.ac.uk/id/eprint/18400

Jeske, D., \& Santuzzi, A. M. (2015). Monitoring what and how: Psychological implications of electronic performance monitoring. New Technology, Work and Employment, 30(1), 62-78. https://doi.org/10.1111/ntwe.12039

Johnson, N., Li, Y., Tang, F., \& Sarker, S. (2014). Are you watching me? A look at panoptic perceptions surrounding computer monitoring systems. Fournal of Information Technology Case and Application Research, 16(1), 9-26. https://doi.org/10.1080/15228053.2014.912475

Kalaian, H. A., \& Raudenbush, S. W. (1996). A multivariate mixed linear model for meta-analysis. Psychological Methods, 1(3), 227-235. https://doi.org/10.1037/1082-989x.1.3.227

Karasek, R. A. (1979). Job demands, job decision latitude, and mental strain: Implications for job redesign. Administrative Science Quarterly, 24(2), 285-308. https://doi.org/10.2307/2392498

Karim, M. N., Willford, J. C., \& Behrend, T. S. (2015). Big data, little individual: Considering the human side of big data. Industrial and Organizational Psychology, 8(4), 527-533. https://doi.org/10.1017/iop.2015.78 
Khakurel, J., Melkas, H., \& Porras, J. (2018). Tapping into the wearable device revolution in the work environment: A systematic review. Information Technology \& People, 31(3), 791-818. https://doi.org/10.1108/itp-03-2017-0076

Kiziloğlu, M. (2018). A research on the relationship between workplace monitoring and job stress. fournal of Organizational Behavior Research, 3(2), 1-12.

https://www.researchgate.net/publication/330849136

Kolb, K. J., \& Aiello, J. R. (1996). The effects of electronic performance monitoring on stress: Locus of control as a moderator variable. Computers in Human Behavior, 12(3), 407-423. https://doi.org/10.1016/0747-5632(96)00016-7

Kolb, K. J., \& Aiello, J. R. (1997). Computer-based performance monitoring and productivity in a multiple task environment. Journal of Business and Psychology, 12(2), 189-204. https://doi.org/10.1023/A:1025022202211

Kwon, D., \& Reis, I. M. (2015). Simulation-based estimation of mean and standard deviation for meta-analysis via Approximate Bayesian Computation (ABC). BMC Medical Research Methodology, 15(1). https://doi.org/10.1186/s12874-015-0055-5

Lüdecke, D. (2019). esc: Effect size computation for meta analysis (version 0.5.1). https://doi.org/10.5281/zenodo.1249218

Luse, A., \& Burkman, J. (2020). Wearables in the workplace: Examination using a privacy boundary model. Journal of the Midwest Association for Information Systems, 2(2), 7-15. https://doi.org/10.17705/3jmwa.000058

Mahaney, R. C., \& Lederer, A. L. (2011). An agency theory explanation of project success. Journal of Computer Information Systems, 51(4), 102-113. https://doi.org/10.1080/08874417.2011.11645506

Mallo, J., Nordstrom, C. R., Bartels, L. K., \& Traxler, A. (2007). The effect of age and task difficulty. Performance Improvement Quarterly, 20(1), 49-63. https://doi.org/10.1111/j.1937-8327.2007.tb00431.x

Martin, A. J., Wellen, J. M., \& Grimmer, M. R. (2016). An eye on your work: How empowerment affects the relationship between electronic surveillance and counterproductive work behaviours. International fournal of Human Resource Management, 27(21), 2635-2651. 
https://doi.org/10.1080/09585192.2016.1225313

McNall, L. A., \& Stanton, J. M. (2009). Employee location sensing: Implications for security and privacy. In H. R. Rao \& S. Upadhyaya (Eds.), Information assurance, security and privacy services (Vol. 4, pp. 481-499). Emerald.

Mellor, D., Moore, K. A., \& Siong, Z. M. B. (2015). The role of general and specific stressors in the health and well-being of call centre operators. Work, 52(1), 31-43. https://doi.org/10.3233/WOR-141975

Microsoft. (2019). Workplace analytics. https://products.office.com/en-us/business/workplace-analytics

Mitchell, G. (2012). Revisiting truth or triviality: The external validity of research in the psychological laboratory. Perspectives on Psychological Science, 7(2), 109-117. https://doi.org/10.1177/1745691611432343

Möhlmann, M., \& Zalmanson, L. (2017). Hands on the wheel: Navigating algorithmic management and uber drivers' autonomy. In Y. J. Kim, R. Agarwal, \& J. K. Lee (Eds.), Transforming society with digital innovation. Association for Information Systems (AIS). https://aisel.aisnet.org/icis2017/DigitalPlatforms/Presentations/3

Moorman, R. H., \& Wells, D. L. (2003). Can electronic performance monitoring be fair? Exploring relationships among monitoring characteristics, perceived fairness, and job performance. Journal of Leadership \& Organizational Studies, 10(2), 2-16. https://doi.org/10.1177/107179190301000202

Nebeker, D. M., \& Tatum, B. C. (1993). The effects of computer monitoring, standards, and rewards on work performance, job satisfaction, and stress. Fournal of Applied Social Psychology, 23(7), 508-536. https://doi.org/10.1111/j.1559-1816.1993.tb01101.x

Neuberger, O., Allerbeck, M., \& Ulich, E. (1978). Messung und Analyse von Arbeitszufriedenheit: Erfahrungen mit dem 'Arbeitsbeschreibungsbogen (ABB)' [Measurement and analysis of job satisfaction: Experiences with the 'Arbeitsbeschreibungsbogen (ABB)']. Huber.

Nishii, L. H., Lepak, D. P., \& Schneider, B. (2008). Employee attributions of the "why" of HR practices: Their effects on employee attitudes and behaviors, and customer satisfaction. Personnel Psychology, 61(3), 503-545. https://doi.org/10.1111/j.1744-6570.2008.00121.x 
Noortgate, W. V. den, López-López, J. A., Marín-Martínez, F., \& Sánchez-Meca, J. (2012). Three-level meta-analysis of dependent effect sizes. Behavior Research Methods, 45(2), 576-594. https://doi.org/10.3758/s13428-012-0261-6

Oz, E., Glass, R., \& Behling, R. (1999). Electronic workplace monitoring: What employees think. Omega, 27(2), 167-177. https://doi.org/10.1016/S0305-0483(98)00037-1

Parker, S. K. (2014). Beyond motivation: Job and work design for development, health, ambidexterity, and more. Annual Review of Psychology, 65(1), 661-691. https://doi.org/10.1146/annurev-psych-010213-115208

Posthuma, R. A., Campion, M. C., \& Campion, M. A. (2018). A taxonomic foundation for evidence-based research on employee performance management. European fournal of Work and Organizational Psychology, 27(2), 168-187.

https://doi.org/10.1080/1359432X.2018.1438411

Pustejovsky, J. (2021). clubSandwich: Cluster-robust (sandwich) variance estimators with small-sample corrections. https://CRAN.R-project.org/package=clubSandwich

Rafnsdóttir, G. L., \& Gudmundsdottir, M. L. (2011). EPM technology and the psychosocial work environment. New Technology, Work and Employment, 26(3), 210-221. https://doi.org/10.1111/j.1468-005x.2011.00270.x

Ravid, D. M., Tomczak, D. L., White, J. C., \& Behrend, T. S. (2019). EPM 20/20: A review, framework, and research agenda for electronic performance monitoring. fournal of Management, 46(1), 100-126. https://doi.org/10.1177/0149206319869435

R Core Team. (2015). R: A language and environment for statistical computing. $\mathrm{R}$ Foundation for Statistical Computing. https://www.R-project.org/

Reilly, S. M. (2010). The use of electronic surveillance and performance measures in the workplace: A qualitative investigation [PhD thesis, Durham University].

http://ethos.bl.uk/OrderDetails.do?uin=uk.bl.ethos.521801

Robinson, C. C. (2020). EPM effects on workplace well-being: The role of personality [PhD thesis, University of Waikato]. https://researchcommons.waikato.ac.nz/bitstream/handle/10289/13508/thesis.pdf Rogers, K. J. S., Smith, M. J., \& Sainfort, P. C. (1990). Electronic performance 
monitoring, job design and psychological stress. Proceedings of the Human Factors Society Annual Meeting, 34(12), 854-858. https://doi.org/10.1177/154193129003401206

Scammacca, N., Roberts, G., \& Stuebing, K. K. (2014). Meta-analysis with complex research designs. Review of Educational Research, 84(3), 328-364.

https://doi.org/10.3102/0034654313500826

Schwarzmüller, T., Brosi, P., Duman, D., \& Welpe, I. M. (2018). How does the digital transformation affect organizations? Key themes of change in work design and leadership. Management Revue, 29(2), 114-138. https://doi.org/10.5771/0935-9915-2018-2-114

Sewell, G., \& Barker, J. R. (2006). Coercion versus care: Using irony to make sense of organizational surveillance. Academy of Management Review, 31(4), 934-961. https://doi.org/10.5465/amr.2006.22527466

Sexton, J. B., Adair, K. C., Leonard, M. W., Frankel, T. C., Proulx, J., Watson, S. R., Magnus, B., Bogan, B., Jamal, M., Schwendimann, R., \& Frankel, A. S. (2017). Providing feedback following leadership WalkRounds is associated with better patient safety culture, higher employee engagement and lower burnout. BMJ Quality \& Safety, 27(4), 261-270. https://doi.org/10.1136/bmjqs-2016-006399

Silverman, M. K., \& Smith, C. S. (1995). The effects of human versus computer monitoring of performance on physiological reactions and perceptions of stress. In Organizational risk factors for job stress. (pp. 181-193). American Psychological Association. https://doi.org/10.1037/10173-011

Smith, M. J., Carayon, P., Sanders, K. J., Lim, S.-Y., \& LeGrande, D. (1992). Employee stress and health complaints in jobs with and without electronic performance monitoring. Applied Ergonomics, 23(1), 17-27. https://doi.org/10.1016/0003-6870(92)90006-H

Sprigg, C. A., \& Jackson, P. R. (2006). Call centers as lean service environments: Job-related strain and the mediating role of work design. Fournal of Occupational Health Psychology, 11(2), 197-212. https://doi.org/10.1037/1076-8998.11.2.197

Stanton, J. M. (2000). Reactions to employee performance monitoring: Framework, review, and research directions. Human Performance, 13(1), 85-113. https://doi.org/10.1207/S15327043HUP1301_4 
Stanton, J. M., \& Julian, A. L. (2002). The impact of electronic monitoring on quality and quantity of performance. Computers in Human Behavior, 18(1), 85-101. https://doi.org/10.1016/s0747-5632(01)00029-2

Stanton, J. M., \& Sarkar-Barney, S. T. M. (2003). A detailed analysis of task performance with and without computer monitoring. International fournal of Human-Computer Interaction, 16(2), 345-366. https://doi.org/10.1207/S15327590IJHC1602/_11

Stanton, J. M., \& Weiss, E. M. (2000). Electronic monitoring in their own words: An exploratory study of employee's experiences with new types of surveillance. Computers in Human Behavior, 16(4), 423-440. https://doi.org/10.1016/s0747-5632(00)00018-2

Story, J., \& Castanheira, F. (2020). How hybrid HR systems affect performance in call centers. Personnel Review, 50(3), 918-934. https://doi.org/10.1108/pr-01-2020-0054

Tamuz, M. (1987). The impact of computer surveillance on air safety reporting. Columbia fournal of World Business, 22(1), 69-77.

Thompson, L. F., Sebastianelli, J. D., \& Murray, N. P. (2009). Monitoring online training behaviors: Awareness of electronic surveillance hinders e-learners. fournal of Applied Social Psychology, 39(9), 2191-2212. https://doi.org/10.1111/j.1559-1816.2009.00521.x

Vanhove, A. J., \& Harms, P. D. (2015). Reconciling the two disciplines of organisational science: A comparison of findings from lab and field research. Applied Psychology, 64(4), 637-673. https://doi.org/10.1111/apps.12046

Varca, P. E. (2006). Telephone surveillance in call centers: Prescriptions for reducing strain. Managing Service Quality: An International fournal, 16(3), 290-305.

https://doi.org/10.1108/09604520610663507

Viechtbauer, W. (2010). Conducting meta-analyses in R with the metafor package. Journal of Statistical Software, 36(1), 1-48. https://doi.org/10.18637/jss.v036.i03

Visser, W. A., \& Rothmann, S. (2008). Exploring antecedents and consequences of burnout in a call centre. SA fournal of Industrial Psychology, 34(2). https://doi.org/10.4102/sajip.v34i2.734

Wang, J., Tian, J., \& Shen, Z. (2013). The effects and moderators of cyber-loafing controls: An empirical study of chinese public servants. Information Technology and 
Management, 14(4), 269-282. https://doi.org/10.1007/s10799-013-0164-y

Watson, A. M. (2008). Electronic monitoring relevance and justification: Implications for procedural justice and satisfaction [Master's thesis]. North Carolina State University.

Watson, A. M., Thompson, L. F., Rudolph, J. V., Whelan, T. J., Behrend, T. S., \& Gissel, A. L. (2013). When big brother is watching: Goal orientation shapes reactions to electronic monitoring during online training. Fournal of Applied Psychology, 98(4), 642-657. https://doi.org/10.1037/a0032002

Wells, D. L., Moorman, R. H., \& Werner, J. M. (2007). The impact of the perceived purpose of electronic performance monitoring on an array of attitudinal variables. Human Resource Development Quarterly, 18(1), 121-138. https://doi.org/10.1002/hrdq.1194

Yost, A. B., Behrend, T. S., Howardson, G., Darrow, J. B., \& Jensen, J. M. (2018). Reactance to electronic surveillance: A test of antecedents and outcomes. Fournal of Business and Psychology, 34(1), 71-86. https://doi.org/10.1007/s10869-018-9532-2 


\section{Appendix}

\section{Included Studies}

The following studies were included in the current meta analysis (for unpublished studies please write to the corresponding author of this meta analysis):

- Adams and Mastracci (2019); Aiello and Svec (1993); Aiello and Kolb (1995); Bartels and Nordstrom (2012); Becker and Marique (2014); Bhave (2014); Carayon (1994); Carlson et al. (2017); Castanheira and Chambel (2010); Claypoole and Szalma (2019); Claypoole et al. (2019); Davidson and Henderson (2006); Day et al. (2012); Douthitt and Aiello (2001); Galinsky et al. (1995); Galletta and Grant (1995); Gosnell et al. (2020); Griffith (1993); Hassan et al. (2019); Henderson et al. (1998); Holman et al. (2002); Holman (2002); Holman et al. (2009); Huston et al. (1993); Irving et al. (1986); Jeske and Santuzzi (2014); Jeske and Santuzzi (2015); Karim et al. (2015); Kiziloğlu (2018); Kolb and Aiello (1996); Kolb and Aiello (1997); Luse and Burkman (2020); Mallo et al. (2007); Mellor et al. (2015); Moorman and Wells (2003); Nebeker and Tatum (1993); Rafnsdóttir and Gudmundsdottir (2011); Robinson (2020); Rogers et al. (1990); Silverman and Smith (1995); Sprigg and Jackson (2006); Stanton and Julian (2002); Stanton and Sarkar-Barney (2003); Story and Castanheira (2020); Thompson et al. (2009); Varca (2006); Visser and Rothmann (2008); Wang et al. (2013); Watson (2008); Watson et al. (2013) 